\title{
Anemia among school-going children in the perspective of socio-economic disparity in Punjab, India
}

\author{
Sukhdeep Kaur, Kiran Bains* and Harpreet Kaur \\ Department of Food and Nutrition, Punjab Agricultural University, Ludhiana, 141004 (Punjab), INDIA \\ *Corresponding author. E-mail: kiranbains68@hotmail.com \\ Received: August 9, 2017; Revised received: September 18, 2017; Accepted: January 27, 2018
}

\begin{abstract}
A survey was conducted to assess socio-economic disparity in the prevalence of anemia among schoolchildren (11-17 years) in few regions of Punjab. Two hundred and ten children from government schools of Punjab were selected and their blood hemoglobin levels were estimated; clinical examination was done for various signs/ symptoms of anemia; and dietary iron intake was analysed and compared with the recommended dietary allowances of ICMR (2010). Analysis of variance followed by Tukey's post-hoc test was applied to assess socio-economic disparity in the prevalence of anemia. Overall, $97 \%$ of the children were anemic, out of which 80 vs. $17 \%$ were moderately and mildly anemic, respectively. Statistically, no significant difference was found in the mean hemoglobin level of the subjects with respect to family income, parent's education and religion, whereas, substantial disparity was noted with respect to caste. Scheduled caste subjects had the highest prevalence rate than general category and Backward Class and Other Backward Class subjects. Dietary iron intake of the children was grossly inadequate, ranging from 35 to $41 \%$ of the ICMR (2010) recommendations. Therefore, it can be established that anemia prevalence depends more on food habits and dietary behaviour of the children than on socio-economic factors. Dietary diversification should be canvassed at the root level, as anemia is likely the result of predominantly starch-based monotonous poor quality diets with minimal amounts of meat, vegetables and fruits.
\end{abstract}

Keywords: Anemia, Punjab, School-children, Socio-economic

\section{INTRODUCTION}

As a result of global burden of disease, interest in micronutrient malnutrition (MNM) has increased greatly over the last few years (Tulchinsky, 2010). MNM is the result of insufficient intake and/or absorption of crucial micronutrients which can contribute to life threatening conditions (Gillespie and Haddad, 2001). Coupled with malnutrition, micronutrient deficiencies especially of vitamin A, Iron and Iodine, also called as 'hidden hunger' have been major nutritional problems in developing countries like India; adversely affecting people's health, performance, income and thereby becoming major impediments to economic development of the nation (Faber and Wenhold, 2007). Attempting to improve the nutritional status without addressing micronutrient deficiencies will not result in optimal growth and function (Fresco, 2002).

The term "Anemia" is used for a group of conditions that result from an inability of erythropoietin tissues to maintain a normal haemoglobin $(\mathrm{Hb})$ concentration on an account of inadequate supply of one or more nutrients leading to a reduction in the total circulating hemoglobin. For the formation of and normal growth of RBCs, iron and vitamins, like folic acid and $\mathrm{B}_{12}$ are essential (Srilakshmi, 2005). Iron Deficiency Anemia
(IDA) is one of the most common micronutrient deficiency disorder seen, especially among infants, children, and adolescents in rapid growth phases (Meshram et al., 2012). Over $70 \%$ of young children in most parts of India and Asia are suffering from Anemia (Kotecha, 2011).

Studies conducted in different states in India on school -going adolescent children revealed that faulty dietary practices like inadequate consumption of fruits and vegetables rich in iron, folic acid and vitamin $C$; poor bioavailability of dietary iron in phytate fibre-rich vegetarian diet coupled with low intake of heme-iron derived from animal foods; poor dietary diversification, an inability to absorb iron due to gastrointestinal tract abnormalities; chronic blood loss; infections and infestations like malaria and hookworm; poor socioeconomic status; unhygienic environment; food insecurity; high cost of health care facilities and the low status of women and lack of parent's education, are the major factors responsible for the high prevalence of anemia in the country (Verma et al., 2012 and Kaur 2014). Although iron deficiency accounts for most of the anemia that occurs in underprivileged environment, multiple other socio-economic causes exist independently or coexist with micronutrient deficiency (Verma et al., 2012). For instance, in India, about 73\% 
of the children aged 5-11 years are affected by anemia; however, a significant gap exists between the prevalence of anemia among children of mothers with no education $(74.5 \%)$ and mother's with 12 or more years of education $(55.4 \%)$, underlying the impact of mother's education in children's nutritional status (NFHSIII, 2005-06). In Punjab, over half (56.6\%) of the children aged 6-59 months, are anemic, slightly lower than the national average. Moreover, children who are stunted, wasted or underweight are much more likely than the other children to suffer from moderate to severe anemia (NFHS-4, 2015-16). Because of these consequences, studies on the magnitude of anemia among school-aged children have paramount importance (Assefa et al., 2014). In the present study, a school-based survey was conducted to assess socioeconomic disparity in the prevalence of anemia among school-children of the few regions of Punjab, India.

\section{MATERIALS AND METHODS}

Setting of the study: For the selection of the subjects, thirty-cluster multistage sampling technique was used. A total of five districts; one each from Majha and Doaba regions and three districts from Malwa region of Punjab were selected targeting school-going children. In the next stage of sampling, two blocks from each district were selected. The last stage included selecting two rural and one urban government school from each block selected in order to have a total random sample size of 210 children in the age group of 11-17 years, representing the school-going children of Punjab state (Fig. 1).

Demographic and socio-economic profile: Information related to age (11-12, 13-15 and 16-17 years),

Table 1. WHO Classification of anemia on the basis of blood hemoglobin level (WHO 2011).

\begin{tabular}{lcccc}
\hline \multirow{2}{*}{$\begin{array}{l}\text { Age } \\
\text { (years) }\end{array}$} & Mild & Moderate & Severe & Non -anemic \\
\hline $11 y$ & $11-11.4$ & & & $\begin{array}{c}11.5 \text { or } \\
\text { above }\end{array}$ \\
$\begin{array}{cccc}12-14 y \\
15 y \quad \text { and }\end{array}$ & $11-11.9$ & $8-10.9$ & $<8$ & 12 or above \\
$\begin{array}{l}\text { Female } \\
\text { Male }\end{array}$ & $11-11.9$ & & & 12 or above \\
\hline
\end{tabular}

Table 2. Mean daily iron intake among school-going children from three cultural regions of Punjab.

\begin{tabular}{lll}
\hline $\begin{array}{l}\text { Age group } \\
\text { (years) }\end{array}$ & $\begin{array}{l}\text { Mean daily iron intake } \\
(\mathbf{m g})\end{array}$ & RDA $^{*}$ \\
\hline $11-12 \mathrm{y}$ & & \\
Girls & $9.4 \pm 2.0$ & 27 \\
Boys & $8.3 \pm 1.9$ & 21 \\
$13-15 \mathrm{y}$ & & \\
Girls & $9.6 \pm 1.7$ & 27 \\
Boys & $11.9 \pm 1.9$ & 32 \\
$16-17 \mathrm{y}$ & & \\
Girls & $9.3 \pm 1.9$ & 26 \\
Boys & $11.6 \pm 1.7$ & 28 \\
\hline
\end{tabular}

*RDA (ICMR 2010) gender (girls and boys), caste (General, SC, BC \& $\mathrm{OBC}$ ), religion (Sikh, Hindu and Others), education (Illiterate, Up to Matriculation and Above higher secondary) and income (Up to Rs. 5000, 5000-10000, 10 20000 and Above 20000) of the parents was recorded.

Clinical examination of the subjects: Information on various signs/symptoms of anemia was recorded as prescribed by Jellife (1966). The classification of anemia as recommended by WHO (2011) was followed for categorization of the subjects (Table 1).

Dietary iron intake: Mean daily iron intake of the subjects was assessed using DietCal software (Kaur, 2015) and compared with the recommended dietary allowances (RDAs) of ICMR (2010). The percent adequacy of iron intake was also calculated.

Hemoglobin determination: The blood samples of the subjects for hemoglobin determination were collected. Hemoglobin concentration in each subject was estimated using the cyanmethaemoglobin method of International Nutritional Anemia Consultative Group (INACG, 1985).

Statistical analysis of the data: To assess socioeconomic disparity in the prevalence of anemia, Analysis of variance (ANOVA) followed by Tukey's posthoc test was applied, using SPSS Windows version 16.0 (SPSS Inc., USA). The mean, standard deviation (SD) and percentages were calculated using standard methods given by Singh et al. (1991).

\section{RESULTS AND DISCUSSION}

Demographic and socio-economic profile: As indicated from demographic and socio-economic profile of the subjects (Fig. 2), the majority of the children were belonging to Sikh religion and were mostly $\mathrm{SCs}$, from

Table 3. Distribution of the subjects on the basis of their blood haemoglobin level (WHO 2011).

\begin{tabular}{|c|c|}
\hline $\begin{array}{l}\text { Categories of anemia with hemo- } \\
\text { globin level }(\mathrm{g} / \mathrm{dl})\end{array}$ & Punjab $(\mathrm{N}=210)$ \\
\hline Severe $(\leq 8)<$ only, not $\leq$ & - \\
\hline Moderate (8-10.9) & $167(80)$ \\
\hline \multicolumn{2}{|l|}{ Mild } \\
\hline $11 y(11-11.4)$ & $3(1)$ \\
\hline $12-14(11-11.9)$ & $8(4)$ \\
\hline \multicolumn{2}{|l|}{$15-17 y$} \\
\hline Female (11-11.9) & $14(6)$ \\
\hline Male (11-12.9) & $12(6)$ \\
\hline Total mildly anemic subjects & $37(17)$ \\
\hline Total anemic subjects & $204(97)$ \\
\hline \multicolumn{2}{|l|}{ Non-anemic } \\
\hline $11 \mathrm{y}(\geq 11.5)$ & $1(0.4)$ \\
\hline $12-14 y(\geq 12)$ & $3(1.4)$ \\
\hline $15-17 y$ & \\
\hline Female $(\geq 12)$ & $1(0.4)$ \\
\hline Male $(\geq 13)$ & $1(0.4)$ \\
\hline Total non-anemic subjects & $6(3)$ \\
\hline
\end{tabular}

Figures in parentheses represent percentages 
Table 4. Distribution of school-going children on the basis of their socio-economic status.

\begin{tabular}{lll}
\hline $\begin{array}{l}\text { Socio-economic } \\
\text { indicators }\end{array}$ & $\begin{array}{l}\text { Moderate } \\
\text { anemia }\end{array}$ & $\begin{array}{l}\text { Mild } \\
\text { anemia }\end{array}$ \\
\hline $\begin{array}{l}\text { Family's income (Rs.) } \\
\text { Up to 5000 }\end{array}$ & $63(83)$ & $12(16)$ \\
$5000-10000$ & $63(81)$ & $15(19)$ \\
$\begin{array}{l}\text { Abo00-20000 } \\
\text { Fathe 20000 }\end{array}$ & $24(77)$ & $4(13)$ \\
$\begin{array}{l}\text { Father's education } \\
\text { Illiterate }\end{array}$ & $17(68)$ & $6(24)$ \\
Up to Matriculation & $50(77)$ & $14(21)$ \\
Above higher secondary & $94(78)$ & $23(19)$ \\
Mother's education & $23(96)$ & - \\
Illiterate & & \\
Up to Matriculation & $57(75)$ & $16(21)$ \\
Above higher secondary & $99(84)$ & $17(14)$ \\
Caste & $11(69)$ & $4(25)$ \\
General & & \\
SC & $42(79)$ & $9(17)$ \\
BC \&OBC & $100(83)$ & $21(17)$ \\
Religion & $25(69)$ & $7(19)$ \\
Sikh & & \\
Hindu & $124(83)$ & $21(14)$ \\
Others & $37(73)$ & $13(25)$ \\
\hline
\end{tabular}

Figures in parentheses represent percentages

low-income group families earning less than Rs. 10000/month. Similarly, Census of India (2011) reported that Punjab has the highest percentage of SCs $(32 \%)$ in the country which is nearly two times higher than the national average (16\%). Sikhism and Hinduism form the major religions of the state, others being Islam, Christianity, Jainism and Buddhism, though comparatively low in proportion. Regarding the educational status of the parents, it was noted that even though most of the parents were educated up to matriculation; the number of those without any worthwhile schooling was also quite substantial.

Clinical examination of the subjects: As shown in Fig. 3, the majority $(65 \%)$ of the subjects reported of breathlessness followed by lethargy $(61 \%)$, headache (59\%), loss of appetite, pale skin (51\% each) and pale conjunctiva (50\%). Symptoms such as paleness/ smoothness of tongue, spoon shaped nails were found in a negligible percentage of the subjects, thus indicating that severe form of anemia may not be present among children from Punjab.

Mean daily iron intake: Mean daily iron intake and percent adequacy of the school children from Punjab have been discussed in table 2 and Fig. 4, respectively. Assessment of iron intake of the subjects, revealed that, mean daily intake of the girls vs. boys aged 11 $12,13-15$ and $16-17 y$, was 9.4 vs. $8.3,9.6$ vs. 11.9 and 9.3 vs. $11.6 \mathrm{mg}$; which was found to be 34.8 vs. 39.5 , 35.5 vs. 37.1 and 35.7 vs. $41.4 \%$ of the RDAs as suggested by (ICMR) 2010, respectively. Children from government schools of Punjab might be consuming nutritionally poor quality of food and grossly inade-
Table 5. Socio-economic disparity in the anemic status of the subjects from Punjab.

\begin{tabular}{lll}
\hline $\begin{array}{l}\text { Socio-economic } \\
\text { indicators }\end{array}$ & $\begin{array}{l}\text { Mean } \\
\text { hemoglobin } \\
\text { (g/dl) }\end{array}$ & $\begin{array}{l}\text { F } \\
\text { ratio }\end{array}$ \\
\hline $\begin{array}{l}\text { Family's income (Rs.) } \\
\text { Up to 5000 }\end{array}$ & $10.5 \pm 0.6$ & \\
5000-10000 & $10.4 \pm 0.6$ & $1.406^{\mathrm{NS}}$ \\
10000-20000 & $10.5 \pm 0.8$ & \\
Above 20000 & $10.7 \pm 0.8$ & \\
Father's education & & \\
Illiterate & $10.6 \pm 0.6$ & $2.001^{\mathrm{NS}}$ \\
Up to Matriculation & $10.5 \pm 0.7$ & \\
Above higher secondary & $10.2 \pm 0.6$ & \\
Mother's education & & \\
Illiterate & $10.6 \pm 0.7$ & \\
Up to Matriculation & $10.4 \pm 0.6$ & \\
Above higher secondary & $10.6 \pm 0.6$ & \\
Caste & & \\
General & $10.5 \pm 0.6^{\mathrm{ab}}$ & \\
SC & $10.4 \pm 0.6^{\mathrm{a}}$ & \\
BC \& OBC & $10.7 \pm 0.8^{\mathrm{b}}$ & \\
Religion & & \\
Sikh & & \\
Hindu & $10.4 \pm 0.6$ & \\
Others & $10.5 \pm 0.6$ & $0.861^{\mathrm{NS}}$ \\
\hline
\end{tabular}

*Significant at 5\%, ${ }^{\mathrm{NS}}$ Non-significant, Means sharing same superscript are not significantly different from each other Means sharing different superscript are significantly different from each other (Tukey's HSD, $\mathrm{p} \leq 0.05$ )

quate quantity of green leafy vegetables, vitamin $\mathrm{C}$ rich and non-vegetarian food. Similar results of nutrient intake lesser than RDAs have been reported in a study conducted among rural school-going children (79 years) of Hisar District, Haryana (Sati and Dahiya, 2012). Nutritional quality of diet can be improved by various household characteristics, such as household income, consumption patterns, living conditions and individual's food habits.

Anemic status of the subjects with respect to socioeconomic disparity: Table 4 and 5 presents the prevalence of anemia and mean $\mathrm{Hb}$ levels of the subjects with respect to socio-economic disparity in Punjab, respectively.

While investigating socio-economic disparity in the prevalence of anemia, statistically no significant difference was observed in the mean $\mathrm{Hb}$ levels of the subjects with respect to family income, parent's education and religion, whereas, significant $(\mathrm{p} \leq 0.05)$ difference was observed in the mean $\mathrm{Hb}$ levels of the subjects belonging to different castes. A Tukey post-hoc test further revealed that significant $(\mathrm{p} \leq 0.05)$ difference was found only between subjects belonging to SC vs. $\mathrm{BC} \& O B C$ category; whereas no difference was observed between any other castes.

According to study results, although there was a decrease in the prevalence of anemia as the educational level of the fathers increased; the mean $\mathrm{Hb}$ levels of 


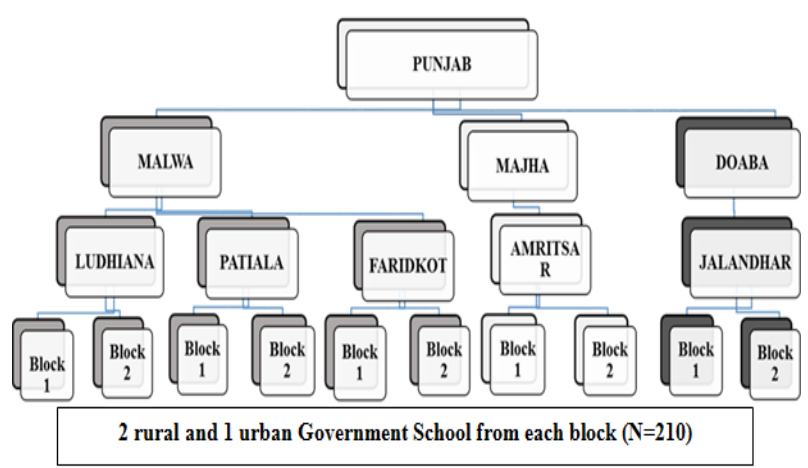

Fig. 1. Sampling design for assessment of anemia among school-going children of Punjab.

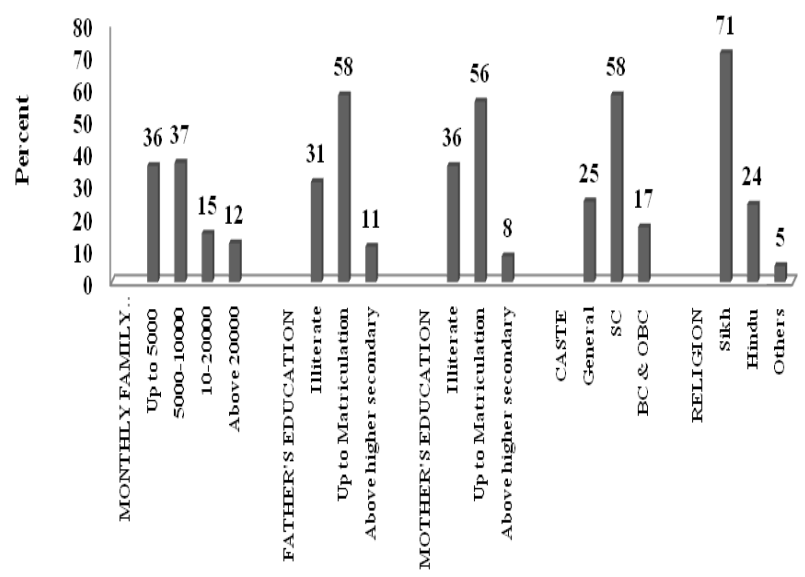

Fig. 2. Distribution of the school children from Punjab $(N=210)$ on the basis of their Socio-economic profile.

the subjects also decreased. Moreover, the difference observed in prevalence rates was not much substantial. Thus, considering both the scenarios, the findings of the study seemed to contradict the general assumption that the educational level of the parents improves the anemic status of the subjects. The fact that there was no significant disparity in the prevalence of anemia among Punjabi children with respect to family income, does not necessarily mean that it is unimportant, since it may influence other variables, such as the quality of the diet itself. The results of the study indicated that to some extent family income can affect the anemic status of the subjects; however, other factors such as food fads and beliefs, faulty food habits, cultural or religious food preferences such as vegetarian diet, some illness and infections may have much more profound effect on the anemic status of the children than income alone.

Though the anemia prevalence rates were slightly lower among children of more educated mothers, insignificant differences in the mean $\mathrm{Hb}$ levels of the subjects with respect to mother's education, could be due to homogeneity of the mother's educational status, as majority of the mothers had low formal education. Other than educational status, several other maternal factors associated with predictors of anemia are lack of

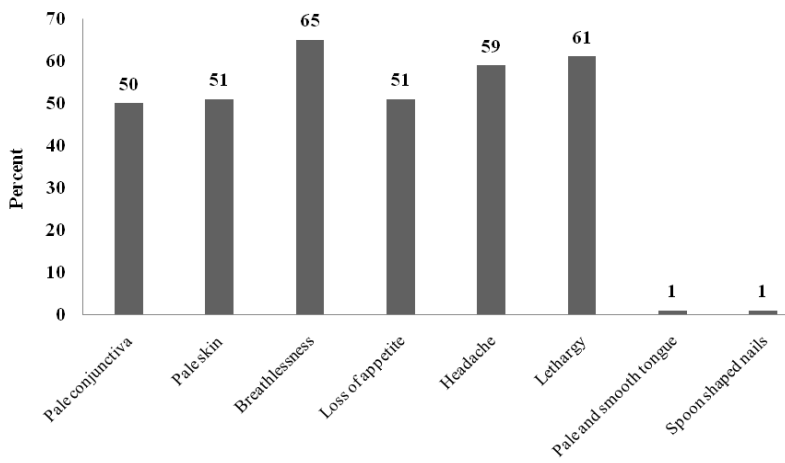

Fig. 3. Clinical signs and symptoms of anemia among the subjects from Punjab.

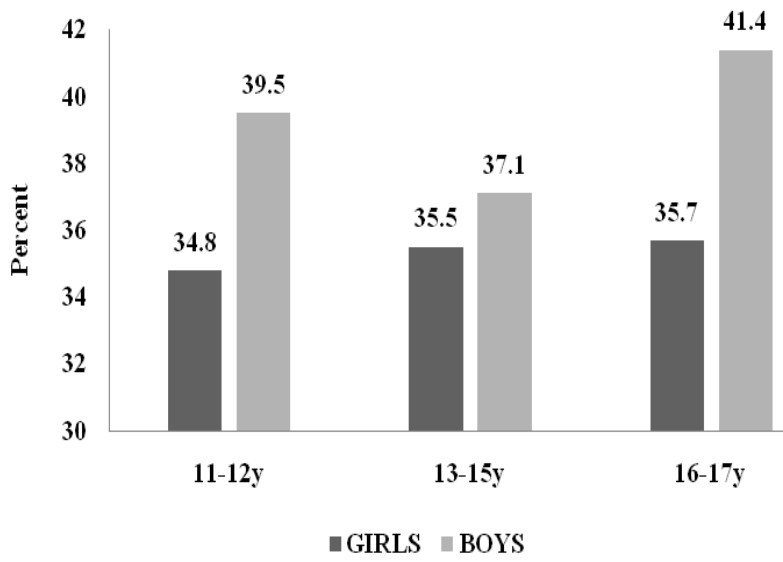

Fig. 4. Percent adequacy of iron intake among school children from Punjab.

awareness among mothers about the problem, poor nutritional practices, age of mothers less than 18 years, higher birth order, delayed antenatal care (ANC) registration and history of post-partum illness, malaria and other parasitic infestations and anemic or employment status of the mother (Sharma and Mahajan, 2014).

Even though the study results indicated that the prevalence of anemia was relatively higher among subjects from other religions (Muslim, Christian and Jains); their mean $\mathrm{Hb}$ levels were found to be marginally higher than Sikh and Hindu subjects. These results are in accordance with DLHS-4 (2012-13) which reported that the prevalence of anemia in Punjab was relatively higher among Christians, followed by Hindus, Muslims and Sikhs. Most religions have dietary rules such as fasting and food taboos that convey religious identity and intensity (Sabate, 2004). Some studies have argued that such food restrictions may undermine the food and nutrition security of women and children in particular by preventing them from consuming nutrient -rich foods (Perez et al., 2013). The results of the study are in contrast to those of few existing epidemiological studies conducted among children in Aurangabad city by Lokare et al., (2012); in western Rajasthan by Bansal et al., (2013); and in India by Baranwal and Roy (2014) which highlighted the significance of reli- 
gion and prevalence of anemia. Culture, religion and the embedded traditional knowledge related to food and health are major determinants of what and how we eat, thus deserves a more prominent place in food and nutrition security research and policy making (Alonso, 2015).

Regarding the anemic status of the subjects with respect to caste, it was found that the mean $\mathrm{Hb}$ values were higher and the incidence of anemia was the lowest among $\mathrm{BC}$ and $\mathrm{OBC}$ category subjects; whereas SC subjects had the lowest mean $\mathrm{Hb}$ values and highest prevalence rates. The results of the study corroborate with DLHS-4 (2012-13) which reported that the prevalence of anemia in Punjab was relatively higher in SC children, followed by ST and OBC children. Similar results are reported by other studies conducted in Varanasi, Odisha and Rajasthan (Richa et al., 2012, Meshram et al., 2014 and Mandot and Bamnawat, 2015), that clearly depicted a very lamentable picture of SC children from India. The possible reason for such a high prevalence of anemia among these communities could be low purchasing power, cultural reasons and lack of knowledge and awareness among mothers regarding child care practices, deprivation of basic environmental quality, limited access to health care, low nutritional intake and poor nutritional perception (Edem, 2009 and Gangadharan, 2011). Caste based social segregation has been linked to socio-economic disadvantage and many adverse health outcomes. These studies indicate the role of social inequalities in the development of anemia.

Evidences from previous literature showed that there are considerable socio-economic variations in the prevalence of anemia among the Indian population; however, such huge disparities could not be observed among Punjabi children because when relative comparison of prevalence rates was studied among children belonging to the lowest family income group and parental education; the results of the study showed that even in the highest family income group and higher parental education, more than $90 \%$ of the children were anemic. Similarly, NFHS-III of Punjab (2005-06), reported that although anemia levels vary somewhat according to socio-economic status, anemia among children is widespread in every group and more than $60 \%$ of children are anemic even if their mother has 10 or more years of education or is in the highest wealth quintile. There is a clear indication of how pervasive anemia is among school children of Punjab, irrespective of socioeconomic disparity. Unfavourable socio-economic and demographic factors are impediments to the efforts in place for the prevention of anemia (Lokare et al., 2012).

Overall prevalence of anemia: According to the WHO classification (2011), out of total 210 subjects surveyed, overall, $97 \%$ of the children from government schools of Punjab were anemic; most of them had a moderate degree of anemia (80\%), while $17 \%$ were mildly anemic and none of the subjects were severely anemic (table 3 ). The incidence of anemia found among Punjabi school children in the study was much higher than children from other states of India (NFHS-4, 2015-16). WHO/UNICEF (1996) has suggested that problem of anemia is of very high magnitude in a community when prevalence rate exceeds $40 \%$ and as indicated from the study results, the prevalence rates in Punjab were far exceeding this suggested percentage limit. The results emphasized that despite the unprecedented economic growth and the serious health and social implications in Punjab, it is still unclear why anemia remains a serious problem in the state. Apparently, multiple interrelated socioeconomic, cultural, environmental and even political factors are expected to be involved.

\section{Conclusion}

Iron intake of the school children was grossly inadequate as compared to Recommended Dietary Allowances. The prevalence of anemia was widespread among Punjabi children, especially among those belonging to low income families (earning less than Rs. 10000 /month); whose parents had a low educational level (Up to Matriculation); those belonging to scheduled castes; and other religions (Muslim, Christian and Jain). However, statistically, no significant difference was found in the mean hemoglobin levels of the subjects with respect to family income, parent's education and religion; whereas, significant disparity was noted in the mean hemoglobin level of the subjects with respect to caste. The scheduled caste children had the lowest mean $\mathrm{Hb}$ values and highest prevalence rate of anemia as compared to other categories. Therefore, it can be established that anemia prevalence depends more on food habits and dietary behaviour of children than on socio-economic factors. Thus, dietary diversification should be canvassed at the root level, as anemia is likely the result of predominantly starch-based monotonous poor quality diets with minimal amounts of meat, vegetables and fruits. Besides dietary changes at household level, addressing anemia urgently requires scaling up effective intervention programs such as supplementation with iron-folic acid or multiple micronutrients and fortification of staple foods or condiments

\section{REFERENCES}

Alonso, E. B. (2015). The impact of culture, religion and traditional knowledge on food and nutrition security in developing countries. Food secure. Working paper No. 30: $1-81$.

Assefa, M. and Kumie, A. (2014). Assessment of factors influencing hygiene behaviour among school children in Mereb-Leke District, Northern Ethiopia: A CrossSectional Study. BMC Public Health, 14: 1000. 
Bansal, B., Takkar, J., Soni, N.D., Agrawal, D.K. and Agarwal, S. (2013). Comparative study of prevalence of anemia in muslim and non-muslim pregnant women of western Rajasthan. Intern. J. Res. Hlth. Sci., 1(2): 47-52.

Baranwal, A. and Roy, N. (2014). Association of Household Environment and Prevalence of Anemia among Children Under-5 in India. Front Public Health, 2: 196.

Census of India (2011). 'Ministry of Home Affairs the Registrar General \& Census Commissioner. New Delhi, Government of India', pp. 1-5. Retrieved August 25, 2014 from http://censusindia.gov.in/Tables_Published/ SCST/dh_sc punjab.pdf.

DLHS-4 (2012-13). 'District Level Household and Facility Survey, India, Punjab, Mumbai, IIPS', pp 4. Retrieved May 25, 2014 from http://rchiips.org/pdf/dlhs4/report/ PJ.pdf.

Edem, D.O. (2009). Vitamin A: A Review. Asian. J. Clin. Nutr., 1(1): 65-82.

Faber, M. and Wenhold, F. (2007). Nutrition in contemporary South Africa. Water SA., 33(3): 393-400.

Fresco, L.O., Baudoin, W.O. and FAO. (2002). 'Food and nutrition security towards human security. ICV Souvenir Paper, International Conference on Vegetables'. Retrieved February 18, 2014 from www.fao.org/ag/agp/ agpc/doc/reports/icv02e90spe.pdf.

Gangadharan, K. (2011). Nutritional Deprivation of children in Rural Kerala: An Inter Caste Analysis. IPEDR., 5: 122-127.

Gillespie, S. and Haddad. (2001). 'Attacking the Double Burden of Malnutrition in Asia and the Pacific. ADB Nutrition and Development Series Number 4. IFPRI', pp 8-10. Retrieved September 11, 2013 from www.adb.org/sites/default/files/publication/27917/ double-burden-malnutrition-asia-pacific.pdf.

ICMR (2010). Nutrient requirements and Recommended Dietary Allowances for Indians', pp 332. Retrieved November 13, 2011 from www.icmr.nic.in/final/RDA2010.pdf.

INACG (1985). Measurements of iron status. Pp 78. New York, NY. Nutrition Foundation.

Jellife, D.B. (1966). 'The Assessment of Nutritional Status of the Community. WHO Monograph Series No. 53', pp 50-84. Retrieved March 7, 2011 from www.who.int/ iris/handle/10665/41780.

Kaur, G. (2015). Diet Cal: A tool for Dietary Assessment \& Planning. Profound Tech Solutions. Department of Dietetics, AIIMS, New Delhi, India.

Kaur, K. (2014). Anaemia- a silent killer among women in India: Present scenario. Euro. J. Zool. Res., 3(1): 32-36.

Kotecha, P.V. (2011). Nutritional Anemia in Young Children with Focus on Asia and India. Indian J Community Med. 36: 8-16.

Lokare, P.O., Karanjekar, V.D., Gattani, P.L. and Kulkarni. A.P. (2012). A study of prevalence of anemia and sociodemographic factors associated with anemia among pregnant women in Aurangabad city, India. Ann. Nigerian. Med., 6: 30-34.

Mandot, S. and Bamnawat, S. (2015). Prevalence of anemia among rural school children of Rajasthan. Intern. $J$. Curr. Res. Rev., 7(15): 40-43.

Meshram, I.I., Arlappa, N., Balakrishna, N., Mallikharjuna, R.K., Laxmaiah, A. and Brahmam, G.N. (2012).
Trends in the prevalence of undernutrition, nutrient \& food intake and predictors of undernutrition among under five year tribal children in India. Asia. Pac. J. Clin. Nutr., 21(4): 568-576.

Meshram, I.I., Balakrishna, N., Arlappa, N., Mallikarjun, R.K., Laxmaiah, A. and Brahmam, G.N. (2014). Prevalence of undernutrition, its determinants, and seasonal variation among tribal preschool children of Odisha state, India. Asia. Pac. J. Pub. Hlth., 26(5): 470-480.

NFHS-4 (2015-16). 'National Family Health Survey. International Institute for Population Sciences (IIPS) \& ORC MACRO', pp 6. Retrieved December 21, 2016 from http://rchiips.org/NFHS/pdf/NFHS4/India.pdf.

NFHS-III (2005-06). 'National Family Health Survey. International Institute for Population Sciences (IIPS) \& ORC MACRO', pp 10-11. Retrieved October 18, 2011 from http://rchiips.org/NFHS/NFHS-3\%20Data/VOL1/ Summary $\% 20$ of $\% 20$ Findings $\% 20(6868 \mathrm{~K})$.pdf.

Perez, M., Guillermo. and Garcia, N.P. (2013). Nutritional Taboos among the Fullas in Upper River Region, The Gambia. J. Anthropol., 2013: 9.

Richa., Mishra, C.P., Kaushik, A., Ahamad, A., Gupta, A.K. and Singh, S. (2012). Prevalence of Anemia in Rural Adolescent Girls of Varanasi, India. J. Prev. Soc. Med., 43(1): 113-116.

Sabate, J. (2004). Religion, Diet and Research. British Journal of Nutrition, 92 (2): 199-201.

Sati, V. and Dahiya, S. (2012). Nutritional Assessment of Rural School-going Children (7-9 years) of Hisar District, Haryana. OMICS., 1: 363.

Sen, A. and Kanani, S. (2006). Deleterious functional impact of anemia on young adolescent school girls. Indian Pediatr., 43(3): 219-226.

Sharma, B.R. and Mahajan, H.D. (2014). A Comparative Study of Alternate Iron and Folic Acid Supplementation Regimes in Childhood Anaemia. Nat. J. Med. Res., 4(1): 33-36.

Singh, S., Bansal, M.L., Singh, T.P. and Kumar, R. (1991). Statistical Methods for Research Workers. Kalyani Publishers, New Delhi, Ludhiana.

Srilakshmi, B. (2005). Dietetics: Nutritional Anaemia, New Age International (P) Limited, Publishers, $5^{\text {th }}$ ed., New Delhi, pp 126-136.

Tulchinsky, T.H. (2010). Micronutrient deficiency conditions: global health issues. Public Health Reviews, 32 (1): 243-255.

Verma, P., Shraddha, S., Archna, G., Ashutosh, K. and Ahilesh, K. (2012) Prevalence of anaemia in adults with respect to socio-demographic status, blood groups and religion in North Indian Population. Int. J. Biol. Med. Res., 3(4): 2422-2428.

WHO (2011). 'Haemoglobin concentrations for the diagnosis of anaemia and assessment of severity', Retrieved January 28, 2012 from http://apps.who.int/iris/bitstream/ 10665/85839/3WHO NMH NHD MNM 11.1 eng.pd f?ua $=1$

WHO/UNICEF (1996). 'Indicators for assessing iron deficiency and strategies for its prevention. Draft based on a WHO/UNICEF', pp 26. Retrieved April 16, 2011 from http://apps.who.int/iris/bitstream/10665/66914/1/ WHO NHD 01.3.pdf?ua $=1$. 